\title{
El Petén guatemalteco en 1840: confluencias de una macrorregión desde la perspectiva inglesa
}

\author{
The Peten in 1840: Confluences within a Macro-region \\ from an English Perspective
}

\author{
LoRena CAREAGa Viliesid / lorena.careaga@gmail.com \\ Universidad del Caribe
}

\section{Resumen / Abstract}

El artículo analiza el informe de Patrick Walker y el diario personal de John Caddy, oficiales que encabezaron la expedición inglesa a Palenque en 1839-1840, con especial énfasis en sus descripciones del Petén guatemalteco y de una escasamente estudiada macrorregión. Se trata de dos documentos poco conocidos y nunca traducidos al castellano que proporcionan un sinfín de datos sobre la vida cotidiana según la experimentaron sus autores en su recorrido desde Belice a Flores y a lo largo del Usumacinta hasta Laguna de Términos. Cada uno, a su estilo y desde su punto de vista, traza el cuadro de una zona caracterizada por la explotación maderera; la abundancia de recursos naturales; las relaciones comerciales con la colonia de Honduras Británica; la explotación de la mano de obra; la inmigración extranjera, y los complejos vínculos sociales en medio de la enorme diversidad étnica y cultural que caracterizaba a esa macrorregión a mediados del siglo xIX.

Palabras clave

Belice, siglo xIx, Palenque, Petén guatemalteco, viajeros, Yucatán.
This paper analyses Patrick Walker's official report and John Caddy's personal diary, written during the English expedition to Palenque in 1839-1840, with special emphasis on their description of the Guatemalan Petén, and of sparsely studied macro region. These two little-known documents, never translated into Spanish, provide a host of information about everyday life as experienced by its authors on their journey from Belize to Flores (Guatemala), and from there along the Usumacinta river to Laguna de Terminos. Each text in its own particular style and viewpoint, maps out the picture of a territory characterized by the exploitation of tropical woods, the abundance of natural resources, commercial and productive relationships with the colony of British Honduras, the exploitation of labour, foreign immigration and complex social ties in the midst of an enormous ethnic and cultural diversity, characteristic of this macro-region during the 19th century.

\section{KeYWORDS}

Belize, Nineteenth Century, Palenque, Guatemalen Peten, Travellers, Yucatán. 


\title{
Le Petén guatémaltèque en 1840 : confluences dans une macro-région depuis une perspective anglaise
}

\author{
Het Peténgebied in Guatemala in 1840: samenstromingen \\ in een macrogebied vanuit Engels perspectief
}

\author{
LORENA CAREAGA VILIESID / lorena.careaga@gmail.com \\ Universidad del Caribe
}

\section{Résumé / Samenvatting}

L'article analyse le rapport de Patrick Walker et le journal personnel de John Caddy, officiers à la tête de l'expédition anglaise à Palenque en 1839-1840, en mettant l'accent sur leurs descriptions du Petén guatémaltèque, macro-région rarement étudiée. II s'agit de deux documents peu connus, qui n'ont jamais été traduits en espagnol, et qui fournissent un grand nombre de données sur la vie quotidienne, telle que l'ont expérimentée les deux auteurs dans leur voyage du Belize à Flores et le long de la rivière Usumacinta jusqu'à la Lagune de Términos. Chacun, avec son style et son point de vue, retrace les spécificités d'une zone caractérisée par l'exploitation forestière, I'abondance de ressources naturelles, les relations commerciales avec la colonie du Honduras Britannique, I'exploitation de la main d'œuvre, l'immigration étrangère et des relations sociales complexes, marquées par la grande diversité ethnique et culturelle de cette macro-région au milieu du XIXème siècle.

\section{Mots-CLÉS}

Belize, XIXème siècle, Palenque, Petén guatémaltèque, voyageurs, Yucatan.
In dit artikel worden het verslag van Patrick Walker en het privé dagboek van John Caddy geanalyseerd, de twee officiers die de Engelse expeditie naar Palenque aanvoerden in 1839-1840, met speciale aandacht voor hun beschrijvingen van het Peténgebied in Guatemala en van een nauwelijks bestudeerd macrogebied. Het betreft twee weinig bekende documenten, nooit in het Spaans vertaald, waaruit eindeloos veel gegevens gehaald kunnen worden over het dagelijks leven zoals de schrijvers dat meegemaakt hebben gedurende hun tocht van Belize naar Flores, langs de Usumacinta tot aan de lagune Términos. Elke schrijver schetst vanuit zijn eigen gezichtspunt een beeld van een zone gekarakteriseerd door de houtexploitatie, een overvloed aan natuurlijke grondstoffen, handelsbetrekkingen met het koloniale British Honduras, de uitbuiting van het werkvolk, immigratie uit het buitenland en ingewikkelde sociale allianties te midden van de enorme etnische en culturele diversiteit waardoor dit macrogebied halverwege de negentiende eeuw gekenmerkt werd.

SLeutelwoorden

Belize, negentiende eeuw, Peténgebied van Guatemala, reizigers, Yucatan. 


\section{Introducciōn}

Con el impacto de la Revolución Industrial, la competencia entre las potencias mundiales -concretamente Gran Bretaña, Francia, Estados Unidos y Alemania- por mercados potenciales, tanto para hacerse de materias primas como para colocar sus productos manufacturados, se volvió cada vez más intensa. La construcción y el control de un canal que comunicara los océanos Atlántico y Pacífico llevaron a estos países a considerar cuatro posibles rutas, que debían ser investigadas y negociadas: Darién y Chagres en Panamá, Tehuantepec en México y el río San Juan en Nicaragua. Una coyuntura se les presentaba especialmente favorable y no dudaron en aprovecharla: la inestabilidad política de España tras la invasión napoleónica y las guerras de independencia de América Latina, por un lado, y por otro, la propia situación de desequilibrio y caos que afectaba a México y Centroamérica. La apertura de un gran mercado para todo tipo de proyectos estaba en ciernes: una América Central pletórica de nuevas tierras que explorar, de ricos recursos naturales que explotar y, por si fuera poco, mediante un muy factible canal interoceánico.

Sin embargo, este ambiente de descubrimiento y expansión se ubicó no en el centro sino alrededor, en la periferia, de los viajes y exploraciones a Yucatán, Honduras Británica y el Petén guatemalteco. Exceptuando la exportación de palo de tinte desde Laguna de Términos, Isla del Carmen y Campeche a puertos europeos como Liverpool, El Havre y Marsella, misma que determinó su incorporación a los mercados mundiales, el resto de esta macrorregión no resultaba un escenario propicio para inversiones extranjeras ni empresas interoceánicas, pero estaba en el núcleo geográfico de tales inquietudes (Baños Ramírez, 1990; Alcalá Ferráez, 2008). De ahí que varios personajes Ilegaran a ella tangencialmente y como consecuencia de un viaje que tenía otras intenciones y propósitos. Tal fue el caso del estadounidense John L. Stephens y de su acompañante, el inglés Frederick Catherwood; del barón austriaco Emanuel von Friedrichsthal, y de los ingleses Patrick Walker y John Caddy.

8 - Revista Mexicana del Caribe 21 / 2016 (pp. 6-41) 
No resulta sorprendente que estos viajeros -originalmente diplomáticos y oficiales de gobierno- se convirtieran en los primeros exploradores de las antiguas ciudades mayas, puesto que esa época de desarrollo político y económico justo coincidió con un naciente interés por develar los misterios de la antigua civilización cuyas ruinas se encontraban desperdigadas por la selva. Las primeras exploraciones de Palenque, en particular las Ilevadas a cabo por Jean de Waldeck, cuyas ilustraciones publicó Lord Kingsborough, sirvieron para Ilamar la atención de académicos y aventureros por igual. Al escaso conocimiento que se tenía de los mayas se unieron los relatos de buscadores de fortuna, cortadores de madera y comerciantes, historias "contadas y recontadas" que embellecían y exageraban el misterio de las ruinas cubiertas por la selva, habitadas por serpientes y murciélagos y decoradas con mascarones de extraños seres humanos. Hasta de elefantes se hablaba (De Waldeck, 1992).

Como resultado de estas especulaciones, en 1839 se organizaron dos expediciones a Palenque, lugar que se convirtió en el detonante de las investigaciones sobre el pasado maya en el siglo xIx. Una de ellas contaba con el apoyo oficial del gobierno de Estados Unidos y fue puesta en manos de John L. Stephens como parte de una encomienda diplomática a Centroamérica que dejó de tener sentido cuando la confederación se disolvió. La otra, Ilevada a cabo a finales de 1839 y principios de 1840, constituye, a decir de David M. Pendergast(1967, p. 6), "la más temprana expedición arqueológica oficial y gubernamental de que se tiene noticia, organizada exclusivamente con el propósito de explorar Palenque y originada desde Honduras Británica". ${ }^{1}$

Este poco conocido viaje exploratorio, convertido por sus protagonistas en una carrera contra el tiempo para ganarle la partida a Stephens y Catherwood y llegar a Palenque antes que estos supuestos rivales, acabó siendo el pretexto ideal para vislumbrar y evaluar las posibilidades de expansión territorial, control político y desarrollo comercial que los británicos podían ejercer en aquel

\footnotetext{
${ }^{1}$ La traducción de esta y las siguientes citas de Pendergast es de la autora.
} 
territorio. El presente artículo, que surge de la investigación realizada por la autora para su tesis doctoral (Careaga Viliesid, 2015), tiene por objeto analizar las dos principales y, podría decirse, únicas fuentes acerca de tal expedición, no desde el punto de vista arqueológico, sino desde la doble vertiente de la experiencia de un viaje en condiciones precarias a través de una región desafiante, y de la descripción tanto de sus abundantes recursos naturales, como de la vida cotidiana de sus heterogéneos habitantes.

La primera de estas fuentes es el diario del teniente de la ArtiIlería Real y dibujante-artista John Herbert Caddy -más de 250 cuartillas tamaño oficio de intrincada escritura- que obraba en poder de sus descendientes junto con varios dibujos de Palenque, papeles sueltos y datos biográficos. La segunda es el informe oficial del secretario de gobierno Patrick Walker, localizado en los archivos de la Colonial Office en Inglaterra. Gracias a David M. Pendergast (1967), quien recopiló los textos originales de ambos oficiales y los enriqueció con documentos de archivo y artículos del periódico Belize Advertiser, conocemos de primera mano cómo y por qué se llevó a cabo la expedición.

Walker y Caddy son mencionados brevemente en otras fuentes: Elizabeth Carmichael (1973) retoma lo dicho por Pendergast, sin añadir información acerca de Caddy salvo una explicación sobre las acuarelas y dibujos del teniente inglés incluidos en una exposición sobre ingleses y mayas que tuvo lugar en el Museo Británico en 1973. Nigel Bolland (1988), por su parte, no comenta nada nuevo en torno al viaje a Palenque, pero se sirve de las minuciosas descripciones de los expedicionarios ingleses para enriquecer su obra sobre mayas, africanos, criollos y la colonización y continuidades culturales de Belice en el siglo xıx. David Adamson (1979) abunda en los detalles que ya señala Pendergast y añade algunas interpretaciones pertinentes. En 1923, Marshall H. Saville (1928) obtuvo de los descendientes de Caddy su diario e ilustraciones sobre Palenque, todo lo cual fotografió y apuntó de manera sucinta en su ensayo Bibliographic Notes on Palenque, Chiapas. El informe de Walker y 
el diario de Caddy, publicados junto con el estudio introductorio de Pendergast, constituyen las fuentes por excelencia acerca de esta expedición y aún esperan ser traducidos al castellano.

\section{Dos extremos del espectro}

Si bien contemporáneos, de la misma nacionalidad y destinados ambos a labores administrativas y militares en Belice, nuestros personajes no podrían haber sido más distintos. John Herbert Caddy, nacido en la guarnición inglesa de la ciudad de Quebec, Canadá, en 1801, sirvió en numerosos puestos militares en el Caribe: Tobago, Santa Lucía, San Vicente y Honduras Británica, a donde llegó en diciembre de 1838 en calidad de jefe de puerto. En todos estos lugares pasó gran parte de su tiempo pintando paisajes y dibujando escenas de la vida cotidiana. Posteriormente complementaría estas imágenes con las vivencias y observaciones que registró en varios cuadernos. Parece haber hecho ambas cosas - pintar y escribir-con dedicación y esmero, partiendo de bosquejos y de notas y trabajando en ellos hasta lograr un producto terminado, tanto artístico como escrito. A Caddy le interesaba la gente y era un observador afanoso del entorno, según lo demuestran las detalladas descripciones que acotó en su diario. Gracias a ellas se tiene información de la cotidianidad en las plantaciones, del corte de maderas preciosas, del medio natural y los recursos disponibles en Honduras Británica, así como una de las reseñas más vívidas del Belice de aquellos años, de su variada población y del contrabando que existía entre la colonia inglesa y Yucatán. Hay a lo largo de su texto múltiples muestras de ese carácter optimista y despreocupado, un Caddy capaz de disfrutar de la cacería, de la comida exótica, de los bailes, de la música y hasta de los "cigarritos" que le ofrecían las señoritas peteneras, a pesar de las condiciones infames en las que transcurrió su viaje (Pendergast, 1967, 8-17). Sin duda, "era un alma más vivaz [que Walker], buen dibujante y pintor" (Adamson, 1979, p. 127), razón por la cual fue escogido para el viaje. 
Por su parte, Patrick Walker llegó directamente de Inglaterra a Honduras Británica en abril de 1837, acompañando a su hermano James, quien traía una encomienda oficial. Cuando James fue enviado de regreso a Inglaterra, la carrera de Walker como servidor público despegó con su nombramiento de encargado del archivo y a la par asistente de la corte. Al poco tiempo fue designado juez de la Suprema Corte, cargo que mantuvo junto con los otros dos. También siguió escalando puestos militares, alcanzando el rango de mayor. Su meteórica carrera no paró ahí, pues fungió como abogado de la Corona, magistrado de la Bahía de Honduras y tesorero de Hacienda. Finalmente ascendió al puesto de secretario colonial, segundo en importancia después del superintendente. En sus ratos libres, todavía se daba el lujo de pertenecer al Club de Regatas. John L. Stephens, quien conoció a Walker en octubre de 1839, lo describió asimismo como: "Secretario de gobierno, además de sustentar tal lista de cargos que haría a cualquiera de nosotros, grandes pluralistas, sentirnos insignificantes" (Stephens, 1841, p. 14). Para Adamson (1979, p. 127), "Walker era una persona notablemente equilibrada y fidedigna, un modelo de rectitud y aplicación industriosa; no por cierto el tipo de persona que uno elegiría automáticamente como compañero en un viaje a través de las selvas Iluviosas, pero de todos modos mejor que la mayoría cuando se trataba de mantener la disciplina y no perderse". Como bien apunta Pendergast (1967, p. 28), "Walker parece haber hecho a un lado las diversiones normales de la vida en aras del empuje que lo llevó de una posición de importancia menor en las cortes, a un punto en el que se podía decir que, a donde quiera que fuese, dos terceras partes del gobierno de Honduras Británica iban con él".

La expedición a Palenque fue únicamente un breve paréntesis en la vida de ambos oficiales. No solo no tuvo efectos directos en ellos de manera individual, sino que, al parecer, ni siquiera cimentó una amistad. No se ha encontrado evidencia de que se hayan vuelto a ver o de que hubieran establecido una correspondencia cuando sus caminos se separaron. John Caddy regresó a Inglaterra en 1841. 
Poco después se trasladó con su mujer y cinco hijos a Ontario, no muy lejos de su lugar de nacimiento, y no tardó mucho en retomar sus acuarelas y llevar el registro escrito de la vida cotidiana de aquel sitio. Con el tiempo, sus paisajes de Canadá, Escocia, Irlanda, Gales y las Indias Occidentales le dieron cierta fama y su obra comenzó a cotizarse en el mundo del arte, incluyendo sus dibujos de Palenque. Falleció en Hamilton, Ontario, en marzo de 1883, a los 82 años.

La vida de Patrick Walker fue más corta y su muerte más trágica, incluso misteriosa. A su regreso de Palenque, el oficial inglés retomó su meteórica y multifacética carrera, convirtiéndose en concejal y en magistrado. Por algo se le otorgó el título de Honorable en 1841, año en el cual también le fue encomendado viajar a Jamaica para tratar con el gobernador de la isla algunos cambios fundamentales en la administración de Honduras Británica. Llegó un momento en el que la pluralidad de puestos oficiales, con su consiguiente diversidad de salarios, se volvió un tema a tratar por un comité especial. No obstante, y a pesar de las recomendaciones del comité, Walker fue nombrado comisionado y tesorero de la Mosquitia, con la encomienda de mediar en las disputas de la zona con las repúblicas de América Central. Además, se le designó como asesor del rey mosquito, cargo que desempeñó junto con todos sus demás nombramientos hasta mayo de 1843, cuando obtuvo una licencia de nueve meses para ir a Inglaterra.

A raíz de ese viaje, su relación con Honduras Británica terminó definitivamente, al ser nombrado agente de Su Majestad y cónsul general británico de la Mosquitia en abril de 1844. Solo una vez más pisó suelo beliceño, acompañando al rey mosquito a su coronación en la iglesia de Saint John. En su nuevo puesto, Walker se dedicó a defender el territorio de Mosquitia de las invasiones y apropiaciones ilegales de sus tierras por el gobierno y empresarios privados de Nicaragua, así como a administrar el presupuesto que la Corona le había asignado a aquel reino. Incidentes en apariencia insignificantes, como izar la bandera nicaragüense en la localidad de San Juan, con la consiguiente respuesta de Walker de bajarla y 
colocar en su lugar la insignia de Mosquitia, suscitaron la presencia armada de Nicaragua en la zona y la captura de los oficiales que Walker había dejado al mando. El 7 de febrero de 1848, dos navíos británicos fueron despachados para hacerles frente y, según el reporte del vicealmirante Austen, fechado el 5 de marzo y dirigido al secretario del Almirantazgo, "el capitán Loch, con el señor Walker en su propio barco, procedieron a Serapaqui y anclaron allí el día 11. Fue allí que ocurrió el triste fallecimiento del señor Walker. Por desgracia se ahogó mientras intentaba salvarle la vida a un amigo que lo acompañaba en su barco y que había caído por la borda durante la noche. Ambos perdieron la vida" (Pendergast, 1967, p. 199). El London Times publicó una historia muy distinta, afirmando que el barco de Walker había sido rodeado por canoas y que él y otra persona habían caído por la borda en tanto el resto de la tripulación se armaba. El otro individuo fue rescatado, pero Walker falleció el 11 de febrero de 1848.

\section{En medio del torbellino}

La situación política de la región centroamericana en aquellos años no podía haber sido más turbulenta, y en medio de ese torbellino se llevó a cabo la carrera inglesa a Palenque. Por un lado, la unión de varias repúblicas que dio lugar a la Federación Centroamericana y a una precaria estabilidad no duró mucho tiempo y para 1839 se estaba desmoronando. Guatemala, en particular, vivía entre las revueltas a las que la sometieron tanto los federalistas del general Morazán, como Rafael Carrera y sus rebeldes conservadores, quienes finalmente depusieron al gobierno liberal de Mariano Gálvez.

Yucatán no se quedaba atrás, y desde mayo de ese mismo año el levantamiento de Santiago Imán en Tizimín a favor del federalismo desembocaría en la primera separación de Yucatán de México. Como ya lo había hecho antes el general Toro para avanzar la causa centralista, Imán utilizó a los mayas y les dio armas para promover la federalista. Se le unió el tercer batallón activo de Yucatán y su 
rebelión se convirtió en un movimiento campesino y popular, tras ofrecerles también una reducción de contribuciones y el respeto a las tierras de los ejidos. En febrero de 1840 se restableció la Constitución de 1825, después de que Imán y sus aliados vencieran a la guarnición de Valladolid, y que el coronel Anastasio Torrens se pronunciara en Mérida restableciendo el sistema federalista. Una vez reinstalado, el VII Congreso Constituyente declaró a Yucatán libre, independiente y separado de la República Mexicana, en tanto existiera el centralismo en el país.

En tal entorno, Honduras Británica representaba una especie de oasis. Belice, con su escasa población de 552 familias según el censo de 1839 (Burdon, 1952), se mantenía aislado de los conflictos regionales y estable dentro de sus actividades productivas. Una de las más sobresalientes -si no es que la más importante- era el corte de caoba y otras maderas duras y preciosas para abastecer el floreciente mercado europeo de los ferrocarriles. Constituía, además, un cruce de caminos en el comercio regional, una especie de Hong Kong de la región centroamericana, que recibía y distribuía una diversidad de productos provenientes de Inglaterra. Sus propios problemas con los países vecinos - por ejemplo, la determinación de límites fronterizos entre la colonia y el territorio mexicano- pasaban casi desapercibidos en medio del caos circundante. En cuanto colonia, estaba lejos de resultar tan atractiva como Jamaica o las Bahamas, donde mercados bulliciosos y puertos concurridos daban cita a multitud de viajeros, soldados, comerciantes y aventureros procedentes de todo el orbe. Honduras Británica era más bien un sitio alejado y algo escondido. Adamson (1979, pp. 124-125) lo califica como "uno de los lugares menos plausibles del Imperio Británico, un apeadero lodoso en una región donde los intereses británicos a lo sumo nunca fueron más que sólidamente ambiguos". El propio Caddy reconocía en su diario que:

En la actualidad hay poca actividad social en Belice, siendo que sus principales habitantes son comerciantes o cortadores de caoba 
que disponen de poco tiempo para divertirse. No obstante, en Navidad, cuando la milicia y la flotilla llegan durante dos semanas a hacer prácticas de entrenamiento, surge una ronda de alegría. En esta estación del año casi toda la población se reúne en la ciudad de Belice, que se convierte en escenario de ruidoso júbilo [Pendergast, 1967, p. 24]. ${ }^{2}$

Siendo capitán del puerto en 1839, Caddy hizo varios dibujos y bosquejos de la ciudad -de los cuales sobreviven solo dos- y narró en su diario lo que más le llamaba la atención, que prácticamente era todo. Describió con entusiasmo y lujo de detalles las costas y cayos, vías fluviales y lagunas, en especial la abundante pesca, las cadenas montañosas y la selva que las cubría, la vida cotidiana en las plantaciones y sus productos, además de algunas plantas nativas y sus usos. Acerca de la ubicación del asentamiento, proporcionó información interesante:

El lugar es quizá el mejor que se hubiera podido escoger en lo que a su posición céntrica se refiere, ya que está a medio camino entre Yucatán y Guatemala, países en donde la mayoría de los productos británicos que llegan a Belice encuentran un mercado muy receptivo. El comercio con Yucatán era prácticamente todo de contrabando hasta hace muy poco, cuando los yucatecos se declararon independientes de México y abrieron sus puertos a las importaciones de otros países con un rango de impuestos muy reducido [Pendergast, 1967, p. 21].

Al igual que Caddy, Walker abundó en su informe acerca de la producción maderera, principal actividad económica de la colonia y una de sus alternativas más explotables y básicas. En su celo de funcionario colonial y con una expresión mucho más fría y escueta que su compañero, Walker aprovechó la expedición para hacer un dictamen del potencial agrícola, maderero y comercial de la región selvática comprendida entre la colonia inglesa y el Petén, así como la viabilidad de rutas que la conectaran con Yucatán y con Isla del

${ }^{2}$ La traducción de esta y las siguientes citas de Caddy es de la autora. 
Carmen. Intentaba proveer información que sirviera a la apertura de mercados, tal como la mentalidad imperial británica de la época los concebía, es decir, bajo la influencia y el control inglés.

\section{La organización de la expediciōn}

Fueron precisamente los cortadores de caoba, que se internaban por senderos en la selva y llegaban hasta parajes desconocidos, quienes primero se toparon con los restos de las antiguas ciudades mayas y reunieron un creciente y Ilamativo corpus de información. Se requirió, sin embargo, de un catalizador para espolear a los ingleses a llevar a cabo una expedición a Palenque, y tal fue el arribo a Belice, el 30 de octubre de 1839, del bergantín Mary Ann, con John Lloyd Stephens y Frederick Catherwood a bordo. Los viajeros fueron recibidos por el superintendente de la colonia, el coronel Alexander MacDonald, y por el propio Patrick Walker en calidad de secretario colonial, quienes se enteraron de sus planes de visitar Copán en primer lugar y Palenque inmediatamente después, y es posible que a raíz de esa entrevista MacDonald concibiera el proyecto de realizar una expedición inglesa a Palenque y ganarle la partida al estadounidense. Había sin duda otras razones para que la expedición, tan difícil en aquellas condiciones climáticas y geográficas, resultara de todas formas una aventura atractiva:

Un cargo en Belice nunca pudo haber sido popular entre los funcionarios británicos. El clima es húmedo y horrible gran parte del año, y antaño era más que probable que uno muriese de una de las diferentes fiebres allí muy difundidas; y además, estaba el deprimente sentimiento de que a uno lo enviaban a servir en un cul-de-sac del Imperio. Cuando se trataba de hombres de temple, como era a menudo el caso de los funcionarios británicos del siglo XIX, la mejor reacción era la actividad, lo cual quizá explique la imagen optimista que ellos tenían de las perspectivas imperiales en América Central. Las oportunidades eran muy evidentes: el Imperio Español se había derrumbado a principios de la década de 1820, y diferentes fuerzas 
luchaban por imponerse en el caos que persistió después durante muchas décadas. El cónsul británico en la República Centroamericana durante la década de 1830 y 1840, Frederick Chatfield, un constructor palmerstoniano del Imperio, quería imponer la creación de un protectorado británico que abarcara lo que ahora son los estados soberanos de Guatemala, Honduras, El Salvador, Nicaragua y Costa Rica. Desde Belice, donde el borracho Robert, Rey de la Costa Mosquito (que se extiende a lo largo de las costas caribeñas de Honduras y Nicaragua) había sido coronado en la catedral anglicana de ladrillo rojo, varios funcionarios habían avanzado para imponer a los súbditos, los indios mosquitos-sambos, aliados desde hacía dos siglos, la tutela británica directa. Con este mismo espíritu se inició lo que ha dado en Ilamarse la "Carrera hacia Palenque" [Adamson, 1979, pp. 125-126].

Detrás de la expedición inglesa había una indudable rivalidad diplomática, designios políticos, intereses económicos poderosos, así como un gran afán de competencia y victoria. El dominio de la Gran Bretaña sobre ciertas áreas de la región centroamericana, incluyendo Belice, había ya entrado en competencia y confrontación con la Doctrina Monroe y el esfuerzo de Estados Unidos por sentar sus reales en una América que debía ser para los americanos. Mientras jugaban el juego diplomático hacia el exterior, los ingleses estaban consolidando su potestad sobre Honduras Británica, haciendo oídos sordos a los reclamos territoriales de México y expandiendo una de por sí pujante explotación de los recursos maderables de la colonia.

Una vez que Stephens y Catherwood prosiguieron su camino rumbo a Guatemala, el superintendente comenzó rápidamente las preparaciones de la expedición. No obstante, era tan poco lo que se sabía de aquellos parajes que MacDonald desconocía el nombre correcto del lugar al que se dirigirían y acabó llamándolo "Polenki". Otro tanto podría decirse de la prensa local. El ambiente de competencia entre ambas expediciones creció gracias a diversos artículos que publicó el Belize Advertiser durante noviembre y diciembre 
de 1839. El diario, sin embargo, no parecía tener clara la razón y meta de la expedición: "El objeto de la misión de estos caballeros es, creemos, inquirir sobre de la verdad acerca de la destrucción de la Provincia de Palanque [sic] así como visitar el río Tobasco [sic], y conocer los aspectos políticos y comerciales de la nueva república de Centroamérica. A través de la talentosa pluma del Sr. Walker esperamos encontrar una respuesta a nuestras dudas con relación a lugares de los que hay tantas noticias extraordinarias" (Pendergast, 1967, pp. 32-33). ${ }^{3}$

Con todo y la ventaja temporal de que pudieran gozar, Walker y Caddy distaban mucho de estar tan preparados como Stephens y Catherwood. Los ingleses tuvieron que hacerlo a marchas forzadas y planear su derrotero en plena temporada de Iluvias, lo que dificultaba enormemente el viaje por el río. Es muy reveladora la forma en que se aprovisionaron para la expedición, sin olvidar las cuentas, espejitos y abalorios para intercambiar con "los nativos"; a diferencia del abogado estadounidense y del artista inglés, que tenían un claro interés científico para lo cual se alistaron, los oficiales de la colonia británica marcharían como si la suya fuese una expedición militar:

A pesar de que la primera etapa del viaje la harían con una fuerza de veintinueve hombres, la necesidad de viajar por el río dictaba que la cantidad de provisiones no fuera mucha, y la expedición comenzó con la expectativa de que habría manera de abastecerse de comestibles a lo largo del camino. Walker se encargó de comprar los alimentos necesarios, incluyendo algunos productos fáciles de llevar, además de barriles de puerco y harina. A estos se añadieron una despensa de artículos básicos, ron y una cierta cantidad de brandy, misma que sustituiría la ración diaria de ron de los líderes de la expedición, cuyos paladares encontraban desagradable la

\footnotetext{
${ }^{3}$ Stephens y Catherwood, que estaban plenamente enterados del plan de MacDonald, como también supieron con anterioridad de los planes de Emanuel von Friedrichsthal y de Benjamin Norman para visitar Chichén Itzá antes que ellos, no parecen haber entrado en tal competencia ni haber tenido mucha prisa en ser los primeros en Ilegar ni a Chichén Itzá, ni a Palenque, aunque Stephens manifestó su preocupación -infundada- de que los ingleses pudieran impedirles el acceso a este sitio.
} 
barata bebida destilada. Sillas de montar, cuchillos, cacerolas, tela para lonas, medicinas, camisas rojas para los soldados y sirvientes, sombreros, mocasines, remos, cuerdas, aceite y pabilos, y una miríada de artículos esenciales fueron recolectados, mientras se fabricaban cajas con cerraduras para todo el bastimento. Finalmente, Walker consiguió de entre las propiedades de un ciudadano recientemente fallecido, dos brújulas y algo de joyería de fantasía para ser distribuida entre los nativos que encontraran en el camino. Además de ayudar con el aprovisionamiento, Caddy se procuró papel, pinturas, lápices, pinceles y todos aquellos artículos necesarios para cumplir con su función de ilustrador de la expedición. También adquirió un cuaderno café empastado en papel, similar a los que había utilizado en las Indias Occidentales, en el cual se proponía registrar las aventuras que sucediesen cada día [Pendergast, 1967, pp. 33-34].

\section{Vicisitudes del camino}

La expedición salió de la ciudad de Belice por el río, el 13 de noviembre de 1839, en lo que probaría ser un largo y difícil recorrido hasta Palenque. Es muy posible que, de todos los viajeros que cruzaron Honduras Británica, el Petén y la cuenca del Usumacinta en el siglo xIx, Walker y Caddy hayan sido los que más sufrieron las inclemencias de la naturaleza y los peligros del camino para llegar a su principal destino.

El diario de Caddy registró cotidianamente el lento avance contracorriente por un río engrosado por las Iluvias. Experimentaron la crecida y caída de sus aguas, que podían inundar los campamentos de manera súbita y bajar de igual forma, así como los rápidos y desniveles que en una ocasión casi los hacen zozobrar. Cada alto en el camino para pernoctar estaba marcado por la existencia, en las márgenes, de algún campamento de cortadores de caoba, o bank, como se le llamaba a las plantaciones, o bien barcadiers, donde los troncos eran maderados o "manufacturados". Caddy (1967, pp. 40-49) describió con lujo de detalles la vida de los caoberos, sus 
tareas en medio de la selva, el modo en que cortaban los árboles, el aprovechamiento de las ramas y de otros árboles que eran derribados en el proceso, los accidentes y más. En estos lugares, los expedicionarios colgaban sus hamacas, se protegían con mosquiteros de la diversidad de tábanos, garrapatas y mosquitos, compartían la cena de tortillas, frijoles y carne -si acaso habían logrado cazar algo- y se levantaban al alba para seguir su travesía después de un desayuno de chocolate, galletas y un poco de vino o aguardiente. A veces se recetaban un "doctor", brebaje hecho de leche bronca, azúcar y brandy. Al despedirse, obsequiaban a sus anfitriones algunos libros -biblias, misales y The Pilgrim's Progress, alegoría cristiana escrita por John Bunyan en 1678-, que por estar en español eran muy apreciados.

Walker tomó como una de sus tareas dar cuenta detallada al superintendente de los recursos naturales aprovechables, las posibilidades agrícolas y madereras, así como de los productos y fertilidad del suelo de las zonas por las que iban pasando:

El río abunda en fluorita de calidad superior, la cual será de gran utilidad a la Colonia como ingrediente en la preparación de la mejor cal; también hay una cantidad inextinguible de arcilla útil en la fabricación de ladrillos, un artículo que ahora resulta preferible a la madera en la construcción de las casas y los almacenes de Belice. Hoy en día, el adquirir ladrillos de Inglaterra no resulta oneroso, dado que los numerosos barcos que llegan a Honduras los traen en grandes cantidades como lastre; pero si se fabricaran en este lugar, ello permitiría que los barcos trajeran carbón en su lugar, el cual será de necesidad primordial cuando las máquinas de vapor se instalen aquí, como pronto debe suceder [Walker, 1967, p. 157]. ${ }^{4}$

A su llegada a la población de Tiger Run, 189 millas río arriba, los expedicionarios, fieles cada uno a su personalidad, observaron y reportaron cosas muy distintas. Mientras que Walker se abocaba a la situación de intranquilidad política, Caddy entró de Ileno en el

${ }^{4}$ La traducción de esta y las siguientes citas de Walker es de la autora. 
espíritu festivo del lugar, donde se organizó un baile a pesar de la escasez de mujeres. Vio por primera vez una marimba y se quejó de la imposibilidad de dormir debido al constante "tom tom" de los negros y sus tambores. Aquel era un punto en el que debían abandonar el río para seguir el viaje a caballo, por lo que Walker aprovechó el regreso de las barcas a Belice para enviar un mensaje al superintendente MacDonald informándole del desarrollo del periplo hasta ese momento. ${ }^{5}$

La partida que continuó la ardua marcha a pie rumbo a Palenque estaba integrada por una asombrosa pluralidad de personajes, representativa de la diversidad étnica y cultural de aquellas localidades. Incluía un anciano negro que hacía las veces de cura, podía leer y escribir, era bilingüe y gozaba de gran influencia sobre los mayas de la región. La indumentaria con la que viajaban los expedicionarios se complementaba con una cantidad mucho mayor de armas de las que tendría un militar en condiciones normales:

Yo llevaba una escopeta de doble cañón y tenía un par de revólveres en mi pistolera, más un machete al costado. Mi atuendo consistía de un Panamá de ala ancha bien calado, una chaqueta cazadora verde de amplios bolsillos, pantalones azules de tela gruesa y mocasines, además de llevar un viejo chaquetón de marinero en la montura en caso de lluvia. La vestimenta de mis compañeros era bastante similar a la mía y nuestros soldados tenían camisas y pantalones azules de tela gruesa. Cada uno iba armado con una pistola y un machete o bien un cuchillo. Los indios iban prácticamente desnudos, pues únicamente vestían un par de pantalones de algodón amarrados a la cintura y enrollados lo más arriba posible. Cargaban sus fardos con una banda hecha de la corteza del árbol Maho, que es muy fuerte, colocada alrededor de su frente; se

${ }^{5}$ En ruta a Duck Run, los expedicionarios se enteraron de la intranquilidad que se vivía a causa de las bandas de revolucionarios peteneros que apoyaban a las distintas facciones políticas guatemaltecas en conflicto, aunque Walker lo percibió más bien como asaltos y redadas por parte de los mayas. Tan no le pareció a este potencialmente peligrosa la situación local que decidió no apostar partidas del $2^{\circ}$ Regimiento de las Indias Occidentales en Tiger Run ni en Duck Run, sino enviar a los soldados de regreso a Belice en las barcas. 
agachaban de cuclillas y así los levantaban. Caminaban sumamente inclinados hacia el frente, ayudándose de un largo cayado para apoyarse. Cada fardo pesaba aproximadamente 70 libras [32 kilos] [Caddy, 1967, pp. 53-54].

A partir de que la expedición dejó el río y siguió por tierra rumbo a Palenque, cambiaron también su forma de avanzar y de acampar. Intentaban pernoctar cerca del agua y de árboles de ramón, el mejor forraje para los caballos y las mulas. Armaban cuatro chozas con lonas y techo de guano donde colgar las hamacas: una para los oficiales blancos, otra para los negros, otra para los indios y una cuarta para los "españoles". Los soldados hacían guardias de cuatro horas alrededor de la fogata, que se mantenía encendida toda la noche para ahuyentar en lo posible a mosquitos y tábanos. Por las mañanas, que eran húmedas y frías, hallaban sus pertenencias cubiertas por una fina capa de rocío. Los expedicionarios entraban en calor con un desayuno de chocolate y galletas mientras cargaban las mulas. Cuando encontraban riachuelos y cascadas, aprovechaban para bañarse, lavar su ropa y aprovisionarse de agua. Los domingos, Walker leía en voz alta un sermón y todos rezaban una plegaria al unísono. El 30 de noviembre de 1839, los ingleses acamparon en Old Bank, lugar conocido en la actualidad como Benque Viejo, el punto fronterizo entre Belice y Guatemala.

\section{A travēs del Petén guatemalteco}

El Petén era una región aislada y abandonada durante décadas por los gobiernos guatemaltecos. Los planes de colonización con inmigrantes europeos se fueron descartando uno a uno ante la idea prevaleciente de que el Petén era un territorio pobre, agreste, que difícilmente podía integrarse al resto de Guatemala. La falta de interés en esta región es incluso evidente en la historiografía que, en general, lo pasa por alto fuera de mencionar algunos datos sobre la etapa colonial temprana. El siglo xix parece no haber existido. En opinión 
de Norman B. Schwartz (1991), la independencia guatemalteca, la toma del poder por los conservadores en 1838 y la Guerra de Castas de Yucatán, que inició en 1847, tuvieron el efecto combinado de incrementar el aislamiento del Petén. Ni siquiera el comercio con Honduras Británica ni la participación de los peteneros en la creciente explotación forestal que sostenía a los poblados mexicanos en la ribera del Usumacinta, desde Palizada hasta Ciudad del Carmen, lograron revitalizar la economía del Petén ni dar salida a sus propios recursos. ${ }^{6} \mathrm{Al}$ parecer, Patrick Walker fue uno más de los visionarios que apreciaron la riqueza natural de la región pero también los inconvenientes para acceder a ella.

A partir del 2 de diciembre, las provisiones de los ingleses comenzaron a escasear, en especial porque se internaron en los humedales, donde no había plantas comestibles ni animales de caza. Perdieron una mula que quedó enterrada en el pantano, acampaban en el lodo y eran constantemente atacados por los mosquitos. Caddy describe la pesada neblina que los rodeaba y la dificultad para conseguir leña suficientemente seca para la fogata. Con expresión sardónica, recomendaba "ampliamente este lugar a aquellos que quieran experimentar el efecto del miasma en la constitución humana" (Caddy, 1967, p. 59). Por su parte, Walker trató de explicar en su informe los retrasos y problemas debidos a las condiciones naturales y climáticas, pero sin omitir sus observaciones acerca de las "cantidades ilimitadas de cedros y caobas de las más gigantescas dimensiones, además de numerosos árboles de caucho indio y otras especies valiosas" (Walker, 1967, pp. 160-161).

El pantano dio lugar a tintales maderables de gran belleza y potencialmente muy productivos si, se apresuró a señalar Caddy, tales sitios hubiesen estado a corta distancia de vías fluviales que permitiesen una fácil y redituable comercialización de la madera.

${ }^{6}$ No fue sino hasta fines del siglo xix que el Petén empezó a desarrollarse, gracias en gran medida a la explotación del chicle, un recurso que también fue decisivo en el desarrollo de otro lugar igual de aislado y repudiado: el Territorio Federal de Quintana Roo. 
Pronto, sin embargo, dejaron los tintales y se vieron rodeados de arbustos espinosos y palmetos, por lo que el avance se hizo todavía más difícil. Finalmente, el 7 de diciembre abandonaron la zona pantanosa y regresaron a bosques de caoba y cedro. Se surtieron de agua fresca, hallaron una vaca perdida que les sirvió de alimento y mascaron caña de azúcar que crecía salvaje desde que alguien la había plantado y abandonado 20 años atrás. No obstante, el sirviente de Caddy, aquejado por fiebres y demasiado enfermo para seguir, falleció. Walker acotó en su informe el encuentro con bandas de mestizos y de indios que portaban arco y flecha, muy similares a la descripción que hicieron otros viajeros de los mayas "huites" que habitaban la costa oriental de la Península, y que no les permitieron el paso, en tanto el comandante del Petén no diera la orden. Ello desembocó en la estancia forzosa, pero agradecida, de los expedicionarios en la isla de Flores, ubicada en el centro del lago Petén Itzá.

\section{Estancia en Petēn Itzá}

Cuando por fin llegaron a Flores, los ingleses descansaron unos días y tuvieron oportunidad de hacer numerosas observaciones del entorno y las costumbres locales. ${ }^{7}$ La estancia en ese espacio fue un bálsamo y un lujo. Caddy comentó que por primera vez desde que salieron de Belice había dormido sin escuchar el zumbido de los mosquitos. Hospedados en una casa propiedad del comandante Ozaeta y alimentados con las viandas que este les enviaba, por el día recibían la visita de los principales habitantes del poblado y por las noches asistían a los bailes que se organizaban en la alcaldía: "La ceremonia de introducción pronto terminó y la persona que fungió como maestro de ceremonias era un hombre muy gracioso de nombre Mendoza Méndez, quien sustentaba el cargo de Secretario de Gobierno y Recaudador de Impuestos, y parecía la per-

${ }^{7}$ Entre sus comentarios resalta el referente al refugio que proveyó el lago Petén Itzá y sus islas a los seguidores de Jacinto Canek, el carismático líder de la insurrección maya que tuvo lugar en Cisteil en 1876. 
sona más informada que habíamos conocido hasta ese momento" (Caddy, 1967, pp. 88-89). Bien puede tratarse de Modesto Méndez, futuro corregidor del Petén e intermediario entre los mayas rebeldes y las autoridades yucatecas en los años iniciales de la Guerra de Castas (Careaga Viliesid, 1998, pp. 46-69). Cabe recordar que Modesto Méndez también realizó las primeras exploraciones de Tikal.

Los ingleses se aprovisionaron de alimentos en el mercado, encontrándolos muy baratos: tasajo (carne de res y de cerdo en tiras curtidas con sal), pavos, arroz, plátanos, maíz y chile. La sal era el único producto caro, pues llegaba al Petén después de atravesar largas distancias, casi siempre desde Campeche o a veces desde Belice. La escasez y alto precio de este condimento provocó en Caddy el siguiente comentario: "Si fuera a utilizarse el epíteto 'no vales ni siquiera un grano de sal' con referencia a un petenero, o al menos a muchos de ellos, tal calificativo podría ser tomado como un cumplido, y podrían creerse más valiosos de lo que en realidad son" (Caddy, 1967, p. 87). Walker concordaba con Caddy a este respecto, aunque sus juicios sobre el carácter moral de los peteneros eran más severos:

Lamento decir que, sin muchas excepciones, los peteneros son en general laxos en sus principios e inmorales en sus hábitos. Los comerciantes beliceños, muy dados a estimularlos [a comprar], con frecuencia otorgan créditos a los peteneros, y esta liberalidad es a menudo mal pagada; se ríen en el Petén de la simplicidad de los beliceños y se congratulan de haberles engañado con una mañosa jugarreta, jactándose de su habilidad para extralimitarse como prueba de su sagacidad, considerando que a mayor la estafa, mejor la burla. Es lamentable ser testigo de una raza tan degradada y resulta triste mirar un lugar que alguna vez poseyó un asentamiento respetable y que muestre en ruinas los vestigios de todos sus emblemas de fortaleza nacional cayendo tan bajo; pero a la sombra de la funesta influencia de un gobierno tan débil y despreciable cualquier reliquia de civilización y fuerza está desapareciendo tan rápidamente que pareciera que en este distrito de la República de Guatemala los indios están predestinados a volverse nuevamente independientes y a 
poseer un derecho único e indisputable sobre la sabana y las selvas, los dominios de sus ancestros [Walker, 1967, pp. 167-168].

Walker no podía saberlo pero, en menos de una década, la Guerra de Castas causaría enorme inquietud y rebeldía entre los mayas del Petén. Para él, los peteneros podían redimirse y sacar lo bueno e industrioso en ellos, siempre y cuando entraran en contacto con los ingleses de Honduras Británica, cuya influencia moral sería muy positiva. La riqueza de selvas y sabanas, que de alguna manera promovía la vida perezosa e inactiva de los peteneros, les resultaría más redituable en dinero, productos y lujos, si se abocaran a construir una carretera que uniera más fácilmente la región con la colonia inglesa y que les permitiera vender su ganado y productos allende sus limitadas fronteras. Los beneficios para Belice tampoco serían desdeñables. La visión de Walker abarca más allá del Petén, imaginando un gran mercado regional para las manufacturas provenientes de la Gran Bretaña:

Una vez construido el camino, no podrá dejar de constituir una fuente de vastos beneficios para la gente del Petén, ya que los mexicanos de Chiapas, Tabasco y los distintos pueblos de las riberas cercanas o divergentes del Usumacinta, quienes son hoy en día los principales compradores de las pocas mercancías que los peteneros traen desde Belice, las adquirirían en grandes cantidades, tan ávidos están de los productos ingleses, convirtiendo al Petén en un depósito intermedio entre Belice y aquellos lugares [Walker, 1967, pp. 168-169].

Walker expresa el sueño imperialista comercial de la Gran Bretaña, con los ingleses a la cabeza por encima de guatemaltecos y mexicanos, pasando sin esfuerzo de la redención del carácter petenero gracias a la influencia civilizatoria inglesa, al aprovechamiento de los envidiables productos y recursos naturales de la región:

Antes de la era de la emancipación africana, las autoridades de Honduras Británica, y con considerable razón, se oponían a una comunicación libre con el Petén debido a las facilidades que los esclavos de 
la Colonia tendrían para escapar. Este obstáculo, sin embargo, felizmente ha dejado de existir, y por nuestro propio interés espero pronto ver un fácil acceso entre estos dos lugares, lo que creará una salida para grandes cantidades de productos británicos, nos proveerá de amplios suplementos de provisiones para nuestra creciente población, y podría, en breve, proveer todo aquello que resulte necesario, por si acaso, en algún momento a futuro, Belice fuera a ser utilizado como una estación de abastecimiento y mantenimiento de nuestra Armada [Walker, 1967, p. 169].

Cuando su informe al fin llegó a manos de las autoridades británicas, los avances y elucubraciones de Walker habrían de costarle, si no una reprimenda, sí una advertencia de parte del ministro de Estado para las Colonias, por tomarse la libertad de expresar una serie de opiniones que no necesariamente convenían a las políticas a gran escala de Su Majestad en América Central y en particular con relación a Yucatán.

\section{De nuevo en camino}

A principios de enero de 1840, después de aproximadamente dos semanas de estancia en Flores, los expedicionarios estaban listos para continuar su senda hacia Palenque, sin saber de la preocupación que por su seguridad se tenía en Belice, en donde no se habían recibido noticias de ellos desde noviembre y su paradero era objeto de numerosas especulaciones. El Belize Advertiser del 4 de enero señalaba que "desde la notificación del regreso de las barcas en las que esos dos emprendedores caballeros se embarcaron para realizar una visita a Palenque, Ilenos de un entusiasmo ansioso de investigación científica y ciertamente digno de sus mentes ilustradas, no hemos recibido inteligencia de su progreso, circunstancia que puede deberse a la estación del año o al estado de caminos rara vez transitados". Los editores del periódico complementaron la nota con un largo comentario acerca de las diferentes teorías que otros exploradores de las antiguas ciudades mayas habían desarrollado 
respecto a los habitantes del Nuevo Mundo y sus orígenes. Caddy (1967, p. 101) añade que: "Si los pobladores de Belice hubieran sabido de la estancia de los expedicionarios en Flores, sus temores habrían sido más bien por el posible agotamiento del erario y menos por la seguridad de los intrépidos exploradores".

El plan de estos era embarcarse rumbo al poblado de San Benito, al otro lado del lago, y de ahí continuar la marcha rumbo a Palenque, vía Sacluc. Los habitantes de Tenosique sabían del inminente arribo de dos "Cabaleros Englis" y su escolta, y salieron a recibirlos junto con el ladrido -calcula Caddy- de una cincuentena de perros. A su llegada a Balancán, localidad a la vera del Usumacinta que tenía unas 150 casas y una población de 600 almas, los ingleses entraron en contacto -sin darse cuenta- con lo que podría haber sido el primer artefacto proveniente de Palenque que habían visto hasta el momento: un recipiente de barro que, a pesar de su forma clásica, a Caddy le pareció demasiado nuevo y muy parecido a los fabricados por los indios (Caddy, 1967, pp. 110-113). Walker, por su parte, continuó trazando un cuadro de tierras no solo ricas en maderas preciosas, sino sumamente fértiles y de clima agradable, reflexionando sobre su adecuado aprovechamiento en beneficio de futuras generaciones (Walker, 1967, p. 171).

La travesía siguió su derrotero rumbo al poblado indígena de Monte Cristo, cercano a Palenque, entre el calor insoportable y los lagartos que habitaban el río. A su llegada, y en ausencia del alcalde, fueron recibidos por "el alcalde de indios", una figura que se antoja trasladada directamente desde los tiempos de la Colonia. Este les proporcionó alojamiento en la casa real y los proveyó de canoas para trasladarse a la hacienda Monte Cristo, estancia ganadera y pequeña plantación de caña de azúcar propiedad de la familia Obrea, que tenía su propio trapiche y fabricaba panela y aguardiente. Ahí desembarcaron para enviar informes a Belice y seguir el trayecto a caballo. Era 26 de enero de 1840 y Caddy empezaba a sentir los estragos del viaje, sobre todo de las picaduras de mosquitos, pulgas y garrapatas (Caddy, 1967, p. 118). 


\section{Por fin la meta}

El 29 de enero de 1840, cuando los ingleses llegaron finalmente al pueblo de Palenque, encontraron que el acceso a las ruinas estaba prohibido sin la presencia de un guía o práctico, cuya tarea era evitar que los antiguos edificios fueran dañados o dilapidados. Aun cuando Caddy no participó en ese primer reconocimiento, pues no podía cabalgar, describió al práctico, el "capitán" don Juan, como un oficial del ejército mexicano a medio sueldo, es decir "nada al día", quien vestía "una especie de uniforme con un par de charreteras de flecos y overoles de cuero con innumerables botoncitos a los lados, mientras que su caballo estaba enjaezado con arreos de cuero negro de tal forma que tenía la apariencia de un rinoceronte" (Caddy, 1967, p. 121). Se trataba nada menos que del guía que había acompañado a De Waldeck en su recorrido por Palenque en 1832-1833, y que luego de atender a Walker y Caddy sería contratado por Stephens y Catherwood, "arreglándoselas así para servir en las tres principales expediciones a Palenque en los inicios del siglo XIX" (Caddy, 1967, p. 121).

Walker fue el primero en acceder a la antigua ciudad maya el 30 de enero de 1840, dos meses y medio después de que la expedición partiera de Belice. Sin embargo, debido al mal tiempo y lluvias constantes, no les fue posible alojarse propiamente en aquel lugar sino hasta el 5 de febrero. Caddy se encontraba tan maltrecho que debió quedarse acostado en su hamaca en el pueblo; pero pronto, sin poder contener su curiosidad, decidió seguirlos y acampar con ellos en medio de los restos pétreos. La estancia de los ingleses en Palenque terminó al cabo de dos semanas, lapso que a Walker le parecía del todo insuficiente para dar una idea más completa y profunda del sitio. Con todo, se animó a lanzar su hipótesis acerca de los orígenes de aquella antigua ciudad:

La fundación de Palenque puede dar lugar a muchas teorías. La que yo estoy más inclinado a considerar es que una gran flota atravesó el Atlántico en busca de territorios no descubiertos. Habiendo 
penetrado por el Usumacinta a través de Laguna deTérminos, los aventureros llegaron hasta acá, y consternados por los peligros por los que habían pasado en su viaje a través de los mares, o bien atraídos por la fertilidad del suelo, se resistieron a regresar y fincaron aquí su morada. También puede haber sido una de las colonias de las que se sabe estaban relacionadas con los asiáticos, y podrían haber tenido comunicación, en tiempo antiguos, con su tierra natal, misma que se puede haber interrumpido por rebeliones, cambios dinásticos y otros accidentes a los que sabemos que el Oriente estaba tan frecuentemente expuesto [Walker, 1967, pp. 178-179].

El 18 de febrero de 1840 dejaron Palenque y emprendieron el largo retorno a Honduras Británica vía Monte Cristo, Palizada, Isla del Carmen y la ruta peninsular, con cartas de recomendación que el cónsul británico de Laguna de Términos, Mr. Shields, les había hecho llegar junto con algunas botellas de vino y otras provisiones que los expedicionarios aceptaron agradecidos. En una misiva al superintendente MacDonald, Walker explicó que su decisión de optar por tal derrotero se debía no solo a que la ruta sería menos difícil y agotadora, sino a la oportunidad de aquilatar el potencial comercial y estratégico que en el futuro tendría Laguna de Términos, "un puerto de gran importancia en el Golfo de México" (Walker, 1967, p. 179). Al mismo tiempo, en Belice las cosas se habían complicado. En una carta fechada el 19 de febrero, y que era más bien una reprimenda, Lord John Russell, secretario de Estado para las Colonias, manifestaba a MacDonald su total desacuerdo con la expedición, con el gasto que esta implicaba y con el hecho de que el superintendente hubiese dispuesto de fondos militares sin autorización (Caddy, 1967, p. 135).

Ajenos a esta situación, los expedicionarios habían dejado la hacienda Monte Cristo con dirección a la hacienda Valparaíso, cercana ya a Palizada, donde encontraron al nuevo cura de la Cabecera y atestiguaron sus pingües negocios:

Aquí [en Palizada] alcanzamos al nuevo padre de la Cabasera [sic], quien estaba visitando los diversos poblados bajo su cuidado, y 
se había estado haciendo de cuotas considerables por bautizos, casamientos y muertes. Nos ofreció la suma que necesitáramos, y si lo dijo como un cumplido español (puesto que siempre dicen que todo lo que es suyo está "a la disposición de usted" [en español en el original], lo que traducido al inglés significa "¿no querrías que fuera cierto?"), no tuvimos oportunidad de saberlo, ya que no lo pusimos a prueba. Nos dijo que nuestro viejo amigo, su predecesor, se había ido a Mérida, habiéndole hecho el ofrecimiento de permanecer [en la Cabecera] para asistirle con las tareas que eran más de lo que un anciano podía atender y dándole una prestación bastante liberal; pero habiendo sido Primer Violín por tanto tiempo, no podía aceptar el puesto en esos términos y se había dirigido a las oficinas centrales en busca de otro curato [Caddy, 1967, p. 136].

El 21 de febrero, los ingleses salieron de Valparaíso y arribaron al día siguiente a Palizada, centro preeminente de cortadores y el más importante depósito de madera del Usumacinta, con 600 habitantes. En tal ruta prácticamente no había poblados, salvo "las chozas ocupadas por Indios Bravos o Indios salvajes, que llevan una vida fácil e independiente cazando y pescando" (Caddy, 1967, p. 138). En Palizada los recibió don Francisco Obrea, el hombre más rico de la región, con un capital, según Caddy, de 100000 dólares. Walker, por su parte, reveló en su informe la pluralidad de nacionalidades que coexistían en la región -"encontré una familia inglesa y tres familias francesas asentadas allí, todas floreciendo en sus vocaciones y prosperando, como cualquiera que realice algo de trabajo lo lograría entre gente tan adicta a los hábitos letárgicos"-, además de mencionar brevemente el conflicto entre Yucatán y el gobierno centralista de México (Walker, 1967, pp. 179-180). El 26 de ese mes se hicieron a la vela en Laguna de Términos y pronto avistaron Isla del Carmen.

Así como proliferaban los extranjeros en una zona aparentemente deshabitada y hostil, como era el Petén guatemalteco y el entronque selvático con el territorio mexicano, también anclaban en la laguna navíos de diversas nacionalidades. Siguiendo su práctica 
de funcionario diligente, Walker describió Isla del Carmen desde el punto de vista de la presencia británica en el puerto, sugiriendo, además, la conveniencia de que algún buque de la armada británica hiciera su aparición en el puerto de vez en cuando, con el fin de proteger mejor los intereses de Su Majestad:

El poblado de Carmen en Laguna es de buen tamaño, los edificios, que pertenecen a los principales comerciantes y cortadores de madera, son grandes y espaciosos, y hay unos siete mil habitantes. A nuestro arribo había dieciséis barcos en el puerto: uno belga, uno francés, uno americano y 13 británicos. Este puerto crece día con día. El vicecónsul, el señor George Shields, un comerciante del lugar, es una persona muy inteligente y parece hacer un gran esfuerzo para mantener los asuntos claros y en orden entre las autoridades mexicanas y los capitanes de los navíos británicos, con quienes ocurren ocasionalmente malos entendidos, y debido a los cuales los funcionarios del puerto y otros oficiales frecuentemente muestran un indebido ejercicio del poder. La presencia ocasional de un barco de guerra británico en Laguna y Campeche restringiría eventualmente todo intento de abusar de los intereses del comercio británico en esta parte del mundo [Walker, 1967, p 182].

El ambiente que se respiraba en Isla del Carmen era a la vez festivo y caótico, ya que "el Carnaval y la Revolución estaban teniendo lugar al mismo tiempo, y creo que esta última era la más absurda" (Caddy, 1967, p. 139). Acostumbrados a la seriedad y dramatismo de las batallas europeas, estos enfrentamientos les parecían graciosos e infantiles. Con su sobriedad acostumbrada, Walker acotó en su informe los preparativos para la salida rumbo a Campeche, obstaculizados por el conflicto entre federalistas y centralistas y por la posibilidad de que los campechanos, todavía centralistas, no creyeran en la neutralidad inglesa. En tanto, Caddy reseñó el corte de madera como la principal actividad del lugar, además de los productos de exportación, en especial el tabaco de excelente calidad y del que él mismo adquirió una buena provisión. Otra información de interés concernía a la venta generalizada de alcohol, los aranceles 
y el contrabando de mercancías inglesas, "cargadas con un impuesto excesivo, que sería casi equivalente a una prohibición si no fuera porque los funcionarios de Hacienda están bastante abiertos al soborno, desde el comandante hasta el más insignificante de los oficiales de la aduana, con la consecuencia de que el contrabando se lleva a cabo a gran escala" (Caddy, 1967, p. 140).

Aunque el trabajo de los indígenas era supuestamente libre, los oficiales ingleses consideraban que existía una especie de esclavitud que los sometía a las haciendas y a los campamentos madereros, sobre todo río arriba, donde el control de las autoridades era aún más laxo que en los puertos. El sistema que Caddy describió -el clásico peonaje por deudas- iba desde el pago al gobierno por la concesión de porciones explotables de selva, hasta la contratación de la mano de obra, a la cual rara vez se le pagaba en efectivo, pues era costumbre adelantarles tela, herramientas y otros artículos, "con una considerable adición de aguardiente", a un precio exorbitante que resultaba imposible de cubrir (Caddy, 1967, p. 140).

Para Walker, el sometimiento por deudas de los mayas en Tabasco y Yucatán era incluso peor y más desesperanzador que el de los africanos sojuzgados por los propios ingleses. Por tal motivo, aquellos indígenas de "indomable independencia", que preferían no engancharse en el corte de maderas, sobrevivían gracias al cultivo de su milpa, a la caza y al trueque ocasional, a fin de "obtener suficiente dinero para pagar sus impuestos al gobierno y adquirir sal y alcohol". Como consecuencia, la mano de obra era bastante cara en toda la cuenca del Usumacinta, además de que se recrudecía con ello la vigilancia y la dureza con las que se controlaba a los indios endeudados. Expresó estas reflexiones junto con su apreciación de la situación social, política y de inseguridad que se vivía en el Petén y a lo largo del Usumacinta, donde, según él, la mayoría de los habitantes deseaba la protección inglesa y la seguridad de la bandera y el gobierno británicos (Walker, 1967, pp. 180-181). Más adelante, durante la prolongada Guerra de Castas, otros funcionarios ingleses confirmarían este mismo deseo, manifestado tanto por los mayas rebeldes como por los yucatecos que buscaban refugio en Belice. 


\section{Colofón a un informe y un diario}

Tras permanecer seis días en Isla del Carmen, los expedicionarios llegaron a Campeche el 5 de marzo de 1840, de donde planeaban salir por mar, desembarcar en Sisal, proceder hasta Mérida y de ahí viajar por tierra hasta la bahía de la Ascensión, desde donde navegarían rumbo a Belice, mientras que el resto de sus acompañantes continuarían por mar desde Sisal rodeando la península hasta Cabo Catoche, y bajarían por la costa oriental hasta Belice. Ninguna fuente secundaria, ni siquiera Pendergast, comenta tales recorridos, pero por las referencias de viajeros posteriores, como Alice Dixon y Augustus Le Plongeon, es probable que fuesen muy utilizados, en particular la navegación costera alrededor de la península por pescadores, comerciantes y contrabandistas. Cabe apuntar que ningún otro viajero extranjero del siglo xIX empleó la ruta terrestre que siguieron Walker y Caddy, aunque quizá se debió a que no había en ella nada que llamara la atención de los exploradores en busca de restos mayas.

Ambos oficiales reportaron brevemente su estancia tanto en Campeche como en Mérida, ciudades que les merecieron los epítetos más admirativos. Por desgracia, el diario de Caddy termina de manera abrupta con una escueta descripción de la catedral de Mérida. No queda anotación alguna del interesante recorrido que debió ser llegar desde Mérida a la bahía de la Ascensión, un logro que ningún otro viajero de la primera mitad del siglo xıx llevó a cabo, ni siquiera Stephens y Catherwood, quienes eligieron otra ruta a la costa oriental. Solo existe un mapa, cuya reproducción en el libro de Pendergast es bastante pobre, pues no se alcanzan a distinguir los nombres de los poblados por los que pasaron, salvo Yaxcabá a medio camino. ${ }^{8}$ Por su parte, Walker también dejó muchos cabos sueltos al final de su informe, a pesar de que afirmaba haber tomado numerosas notas acerca del recorrido por Yucatán, hoy perdidas para la historia (Walker, 1967, p. 185).

${ }^{8} \mathrm{Ni}$ siquiera en comunicación personal con la autora pudo Pendergast proporcionar los nombres que aparecen en el mapa, dado que su copia quedó en manos del editor y nunca la pudo recuperar. 
Los ingleses regresaron finalmente a Belice el 4 de abril de 1840, después de un viaje de 142 días, alrededor de cuatro meses y medio. Tras recibir la documentación de la expedición a Palenque, Lord Russell la aprobó en términos generales, no sin advertir a Walker que se abstuviera de incluir en cualquier publicación sus observaciones de tipo político concernientes a otros gobiernos:

Los dibujos son muy notables y llamativos, y les concedo al señor Walker y al teniente Caddy un gran crédito por el celo y espíritu emprendedor que han evidenciado al encabezar esta expedición. He enviado el informe del señor Walker y los dibujos del teniente Caddy a la Sociedad Geográfica, omitiendo del primero aquellos pasajes en los que el señor Walker comenta sobre la conducta y opiniones políticas de ciertos ciudadanos y funcionarios mexicanos, y también aquellos en que habla del deseo del pueblo de Yucatán por gozar de la protección de un gobierno como el de la Gran Bretaña. Dado que el señor Walker está considerando divulgar [su informe], debo sugerirle que, como funcionario de la Corona, observe gran cautela con relación a esos puntos en cualquier relato que publique [Pendergast, 1967, p. 188].

No obstante el tácito permiso de Lord Russell, o quizá a causa de sus advertencias, ni Walker ni Caddy publicaron nunca sus reportes ni dibujos de Palenque. El único esfuerzo que Caddy Ilevó a cabo para dar a conocer sus ilustraciones fue completarlas cuidadosamente y exhibirlas ante la Sociedad de Anticuarios de Londres en enero de 1842. En una nota manuscrita dice haber leído también su reporte, aunque no hay ningún registro de ello en los archivos de la Sociedad (Saville, 1928, p. 138).

Un sentimiento generalizado de desencanto con toda la expedición permeó las opiniones de los contemporáneos y colegas británicos de los expedicionarios, en gran medida debido al triunfo científico y editorial del estadounidense Stephens. Cronológicamente, sin embargo, Patrick Walker y John Herbert Caddy ganaron la carrera a Palenque, pues cuando Stephens y Catherwood arribaron al poblado de Santo Domingo, ya el prefecto los esperaba y sabía por Walker de 
su inminente llegada. Encontraron la señal inequívoca de la estancia de los ingleses al ver sus nombres inscritos en las paredes del principal edificio de Palenque, como tantos otros viajeros habían hecho antes que ellos y lo harían después los múltiples visitantes y turistas del mundo maya hasta el día de hoy (Adamson, 1979, p. 129).

\section{Conclusiones}

En su papel de viajeros, Walker y Caddy revelan, por un lado, el punto de vista británico y el celo de sus funcionarios, tanto en defensa del imperio como en la búsqueda de coyunturas que mejoraran la vida de la colonia a la que ambos le estaban dedicando su mejor esfuerzo; por otro, se halla en sus textos una visión del todo contrastante entre el Petén y la cuenca del Usumacinta con relación a la Península de Yucatán. Se expresaron sobre esta última de manera sumamente positiva y llena de admiración, salvo en lo concerniente a aquellas regiones donde, al haber pasado más tiempo y en condiciones tan difíciles, pudieron percatarse de realidades que de otro modo les habrían pasado desapercibidas, donde la bonanza del corte de madera beneficiaba a unos cuantos, entre ellos muchos extranjeros, mientras que, por deudas impagables, ataba a los mayas a una situación de sojuzgamiento inhumano. Ello no quiere decir que lo que encontraron de admirable en Campeche y Mérida no lo fuera, sino que no tuvieron la oportunidad de adentrarse en su cotidianidad. Los expedicionarios ingleses no solo no gozaron mas que de una pincelada de la realidad, matizada asimismo por su condición de funcionarios de un gobierno extranjero atendidos por cónsules y gobernadores, sino que su perspectiva estuvo coloreada por la ordalía de una jornada difícil y por su propia condición de ingleses habitantes de un lugar aislado y sencillo como Belice. En comparación, las urbes yucatecas les parecieron atractivas y cosmopolitas, a diferencia de otros viajeros, como De Waldeck y Benjamin Norman, que se mostraron sumamente críticos de su entorno. 
La multitud de nombramientos y cargos oficiales que Walker ejerció de forma simultánea indican al menos una cosa: que fue adquiriendo una enorme experiencia y un conocimiento muy por encima de lo esperado en cualquier oficial británico acerca de Honduras Británica en particular, y de la región centroamericana en general. Sus opiniones, por tanto, aunque menos amenas de leer que las de Caddy, reflejan desde un ángulo maduro y curtido el punto de vista gubernamental, gracias a su personalidad rígida, precisa, observadora y atenta a los detalles. Es posible que Belice careciera de funcionarios idóneos para ocupar todos esos puestos, pero también es evidente que Walker tenía habilidades de liderazgo y la capacidad de hacerse cargo a la vez de una gran cantidad de asuntos diversos.

John Caddy es el cronista de la vida cotidiana, mientras que Patrick Walker representa el ojo clínico del imperialismo. De ahí que sus textos sean tan complementarios como enriquecedores. Entre ambos dejaron a la posteridad una visión en la que el Petén guatemalteco aparece ligado por senderos selváticos y fluviales con los afanes silvícolas de la cuenca del Usumacinta, Isla del Carmen y Laguna de Términos: una macrorregión de gran productividad, intercambio comercial, redes de contrabando, movilidad poblacional y diversidad cultural, donde el palo de tinte y las maderas duras y preciosas, que ya habían comenzado a ser explotadas desde el siglo XVIII, continuaban jugando un papel estelar en la economía y constituían el telón de fondo de complejas relaciones étnicas y laborales. Ello sin olvidar la presencia, en apariencia periférica, de dos polos regionales: Belice y la Península de Yucatán.

Al parecer, por lo acotado en los textos de Walker y Caddy, las intenciones británicas de expansión productiva y comercial sobre el Petén, y aun sobre lugares tan alejados como Laguna de Términos e Isla del Carmen, eran mantenidas a raya por la propia naturaleza del sitio, es decir, por las dificultades que el entorno exhibía para la apertura de caminos de comunicación y rutas de acceso a y transporte de aquellos valiosos recursos naturales. Asimismo resulta 
evidente que el vacío de poder que caracterizaba a toda esa zona, donde las decisiones políticas dependían de individuos que controlaban pequeños cotos y ejercían en ellos su poder sin cortapisas, no propiciaba un escenario adecuado para la expansión territorial. Gran Bretaña habría de preferir otros métodos ante los obstáculos del medio ambiente y aquellos representados por el dominio que en una década más tendrían los mayas sublevados sobre las zonas limítrofes de Belice y Yucatán.

Respecto a este último, si bien varios viajeros del siglo XIX Ilámese oficiales de gobierno, oficiales militares o comerciantes radicados en Belice- propusieron y sustentaron las ventajas de acoger como parte de la colonia las productivas selvas del sur peninsular, en todos los casos el gobierno de Su Majestad respondió, de manera oficial, pero también personal y privada, que tal medida no solo no estaba en sus planes, sino que incluso mencionarla en una publicación resultaría pernicioso y contraproducente. No hay duda de que los británicos se beneficiaron por muchos años de la carencia de un tratado de límites fronterizos con México, pero fue la relación simbiótica que sostuvieron con los sublevados mayas desde 1847 lo que en realidad les brindó utilidades importantes. Aceptar a los mayas y a los yucatecos como súbditos hubiera sido una medida con demasiadas aristas políticas y diplomáticas; para la Gran Bretaña resultaba más conveniente la explotación de los recursos naturales sin los problemas de la posesión territorial. 


\section{Fuentes citadas}

Adamson, D. (1979). El mundo maya. Barcelona: Javier Vergara.

Alcalá Ferráez, C. R. (2008). Asistencia, sanidad y población en la ciudad de San Francisco de Campeche, 1812-1861 (Tesis doctoral inédita). Departamento de Antropología Cultural e Historia de América y de África-Facultad de Geografía e Historia-Universidad de Barcelona, Barcelona.

Baños Ramírez, O. (1990). Sociedad, estructura agraria y Estado en Yucatán. Mérida: Universidad Autónoma de Yucatán.

Bolland, N. (1988). Colonialism and Resistance in Belize. Essays on Historical Sociology. Benque Viejo: Cubola Productions.

Burdon, J. A. (1952). Archives of British Honduras, Volume II 1801-1840. Londres: Sifton Praed \& Co.

Caddy, J. H. (1967). Diario de viaje. En D. M. Pendergast (Comp. y Ed.), Palenque. The Walker-Caddy Expedition to Palenque, 1839-1840, (pp 36-155). Norman: University of Oklahoma Press.

Careaga Viliesid, L. (1998). Hierofanía combatiente. Lucha, simbolismo y religiosidad en la Guerra de Castas. Chetumal: Universidad de Quintana Roo/Consejo Nacional de Ciencia y Tecnología.

Careaga Viliesid, L. (2015). Invasores, exploradores y viajeros: la vida cotidiana en Yucatán desde la óptica del otro, 1834-1906 (Tesis doctoral inédita). Facultad de Filosofía y Letras-Universidad Nacional Autónoma de México, México.

Carmichael, E. (1973). The British and the Maya. Londres: The British Museum.

Pendergast, D. M. (Comp. y Ed.) (1967). Palenque. The Walker-Caddy Expedition to Palenque, 1839-1840. Norman: University of Oklahoma Press.

Saville, M. H. (1928). Indian Notes and Monographs (F. W. Hodge, Ed.), VI(5), Bibliographic Notes on Palenque, Chiapas. Nueva York: Museum of the American Indian/Heye Foundation.

Schwartz, N. B. (1991). Forest Society: A Social History of Petén, Guatemala. Filadelfia: University of Pennsylvania Press.

Stephens, J. L. (1841). Incidents of Travel in Central America, Chiapas and Yucatan (2 vols.). Londres: John Murray. 
El Petēn guatemalteco en 1840 desde la perspectiva inglesa

Waldeck, J. F. de (1992). Viaje pintoresco y arqueológico a la Provincia de Yucatán, 1843 y 1836. México: Consejo Nacional para la Cultura y las Artes.

Walker, P. (1967). The Official Version-Walker's Report. En D. M. Pendergast (Comp. y Ed.), Palenque. The Walker-Caddy Expedition to Palenque, 1839-1840 (pp. 156-186). Norman: University of Oklahoma Press. 